\title{
Poverty, Migration and the Transmission of HIV/AIDS in District Dir Lower, Khyber Pakhtunkhwa, Pakistan
}

\author{
S. Ullah (Sana Ullah)1', A. Naz (Arab Naz)², M. A. Khan (Muhammad Asghar \\ Khan) $)^{3}$, M. H. Khan (Muhammad Hamayun Khan) ${ }^{4}$
}

${ }^{1}$ Lecturer in Sociology, University of Malakand, PK.

${ }^{2}$ Chairman Department of Sociology, Dean Social Sciences,

University of Malakand, PK.

${ }^{3}$ Lecturer in Sociology, University of Swat, PK.

${ }^{4}$ Lecturer in Law, University of Malakand, PK.

\section{E-mail address:}

sana_871@yahoo.com

\section{Reprint address:}

Sana Ullah

Department of Sociology

University of Malakand

Pakistan

Source: Clinical Social Work and Health Intervention

Volume: 12

Issue: 3

Pages: $59-66$

Cited references: 39

\section{Reviewers:}

Roberto Cauda

Institute of Infectious Diseases, Catholic University of the Sacred Heart, Rome, IT

Jirina Kafkova

MSF, Freetown, SL

\section{Keywords:}

Poverty. Migration. HIV/AIDS. Remittances. Globalization. Risks. Vulnerabilities.

\section{Publisher:}

International Society of Applied Preventive Medicine i-gap

CSWHI 2021; 12(3): 59 - 66; DOI: 10.22359/cswhi_12_3_11 (C) Clinical Social Work and Health Intervention

\section{Abstract:}

Poverty, a multifaceted concept has been defined as: hunger; lack of shelter; being sick and not being able to see a doctor; having no access to a job; lack of freedom: fear for the future. Historically, people have migrated from one place to another to increase their livelihood and improve the living standards of their left behind families, while the process of globalization has intensified the movement of people across the world. Although, migration has been an important source of remittance and help in socioeconomic uplift of migrant families, however; it has also negatively impacted migrants and their families. Migrants are exposed to different risks and vulnerabilities at their 
destinations, which exposes them to many other health problems including their exposure of contracting HIV/AIDS. This study was conducted in the District Lower Dir of Khyber Pakhtunkhwa province of Pakistan with the objectives to know the relationship between poverty, migration and transmission of HIV/AIDS. The study was qualitative in nature while the selection of the sample has been made under the purposive sampling technique. Primary data was collected from 12 respondents through in-depth interview using interview guide. The collected information was analyzed thematically in order to clarify the issue under study. The study concluded that migrants: face unsafe environments; lesser access to information and health services; precarious working and living condition; exposure to risky behaviors which put them at risk of contracting the disease.

\section{Introduction}

In general terms poverty is the inability to attain a minimum standard of living and a person who is unable to meet his basic needs is poor. However, poverty is a multidimensional and complex phenomenon and refers to hunger, lack of shelter, being sick and not being able to see a doctor, having no access to job, fear for the future, sense of deprivation and lack of freedom and participation in everyday activities of society (World Bank, 2008; Duy, Erikson, Nguyen Phuong, Hojer and Diwan, 2003; Simonen, 2005). Literary evidences indicate that approximately 1.3 billion people around the world are poor living on less than US $\$ 1.90$ per day (World Bank, 2019, Hughes \& Avoke, 2016), while approximately $70 \%$ of the world poor, deprived and vulnerable people are living in rural areas lacking basic necessities and services of life (Moghadam, 2005). The absences of basic necessities compel people to migrate in search of better economic opportunities (Castles, 1998). Thus, economic factors remain the key determining factor behind migration at global level.

Migration refers to the movement of people from one place to another and taking permanent or semi-permanent residence. The process of globalization and modern communication has radically altered the process and volume of migration, and has made people more aware of the opportunities elsewhere around the world and within national borders (Castles, 2002), and has also made traveling easier and faster than in the past (Castles, 2002). Each year, millions of peo- ple travel within and outside their countries in search of work, better life opportunities, to avoid poverty and to acquire better education. In 2014, there were about 1 billion people living outside their original places of birth or residence (UN Report, 2015; Suliman, 2017), while nearly 150 million of these migrants were economically active (Martin, 2013). In this context, a significant increase was reported in number of migrants. In 2019, there were an estimated 272 million international migrants, comprising almost $3.5 \%$ of world population (Standing, 2008; ILO, 2019). Migration has been a significant source of livelihood for many rural households unable to support themselves through agriculture and local income (Pham \& Hill, 2008).

In developing countries migratory movements are usually between rural and urban areas, and recent estimates have found that in 2020 the major portion of population in developing countries are living in urban areas (Singh, 2009). Further, it is estimated that by 2025 poor countries would earn over US \$140 billion as remittances in a year from migration (World Bank, 2006). In Pakistan, the patterns of both international and internal migration are highly fluid and frequent. labor migration has been regarded as an alternative livelihood opportunity; a source of poverty alleviation; improved life standards for many Pakistani families (Duckett, 2001, Siddiqui, 2005; Piotrowski, 2009). Although, migration is a source of earning and socioeconomic uplift but and not a risk factor in itself for HIV or negative health outcomes, but many factors associated to migration such as: poor living 
condition; poor and dangerous working; social exclusion; lesser or not access to services; exploitation; discrimination; sexual abuse; violence may increase migrants' exposure to HIV and other health related vulnerabilities. In addition, in migrant communities social control is often limited and sexual relationships that are prohibited at home are possible abroad (Davies, Basten, \& Frattini, 2009). The present study is based on the argument that migration is a critical factor in the export and import of HIV, as many migrants return with $\mathrm{HIV}$ infection from $\mathrm{Eu}-$ rope, Middle East and Gulf Countries (Connell, 2006). Although, migration has significant contributions in the transmission of the infection, however; relatively little research work has been done on this aspect of the disease. The current study is broadly investigating the relation between poverty, migration and transmission of HIV/AIDS, however; the study will focus on the following objectives:

\section{Study Objectives}

- To investigate the relationship between poverty and migration

- To find migrants exposure to various health risks at destination

- To know about occurrence of HIV/AIDS transmission among migrants

\section{Theoretical Framework of the Study}

This study utilized varied theories such as Diana Livelihood Theory (1998); Ravenstein (1885) The Law of Migration Lee's (1966) Push and Pull Theory, Oded Stark \& David Bloom New Economics of Labor Migration Theory (1985) in order to develop broader understanding of the issue. Generally, livelihood means social and material capabilities, endowment, abilities, assets, properties and activities (Carney, 1998). Poor people have limited access to accumulation of natural and financial resources as compared to rich people and such conditions expose them to develop risky trends and further compound their poverty (Sherbinin, 2008). The absence of life standard parameters among poor people put them at risks of diseases including HIV/AIDS. And, they are least capable to survive the impact of the disease (Cohen, 2006). Ravenstein Theory of Migration primarily considers migration as the result of economic needs both at place of origin and destination (Skeldon, 1997) and see migration in terms of economic dimensions (Wood, 1982). The push - pull model of migration assumes that migration was mostly based upon rational choice and utilitarian principle both at micro and macro levels (Massey \& Parrado, 1998) and it is argued that variation in wages and capital across countries attracts people from some countries to others (Arango, 2004). In addition, the new economics of labor migration (Massey et al., 1993) see migration as a complex phenomenon and recognize migration not an individual decision phenomenon, rather a combination of rational choice decision making in the family (Stark \& Bloom, 1985). This theory sees migration as a means of mitigating the risks of: a financial shock; to search for diverse and better economic opportunities; to gain access to better economic opportunities; o expand income generation resources. Both international and internal migration is a source to cover the cost of basic needs of life such as food, health, cloths, education etc. In current context, people move from one place to another mostly in search of finding better economic opportunities, which in turn places them in risks of acquiring other disease including HIV/AIDS.

\section{Methods and Procedures}

This study was qualitative in nature and primary data was collected from 12 respondents while applying purposive sampling technique (Adler and Adler, 2012; Patton, 2002). Data was collected from those HIV/AIDS patients who remained migrants (internal, international, \& circular) during their life and have acquired the infection. Further, primary data was collected from 3 Tehsil's of District Dir Lower, i.e. Tehsil Adenzai, Tehsil Timargara, and Tehsil Samarbagh equally (4 respondents from each Tehsil), through in-depth interview using interview guide. For ensuring anonymity of respondents coding was used and their names were not disclosed; while considering the ethical aspect of the study an informed consent form was signed from the respondents in advance (Shamoo \& Resnik, 2009). Collected information were transcribed and presented as primary quotes under various themes in data analysis section supported by secondary data. 


\section{Thematic Discussion}

Data was analyzed qualitatively under various themes. Data was passed from various stages such as: transcription of data; coding interesting features; producing potential themes within data; checking these themes; defining or naming these themes; producing a research report in line with study statement and objectives ((Braun \& Clarke, 2006).

\section{Poverty, Migration and Health Vulnerabilities among Migrants}

In general terms, a person who is unable to meet his/her basic needs or maintain a minimum standard of living is poor. Poverty, a multifaceted concept means:hunger, lack of shelter; having no access to a job; being sick and not able to see a doctor (World Bank, 2008). Poverty also includes social, economic and cultural dimensions, the fear of future and lack of freedom (Deleeck et al., 1992). Literary evidence indicates that at global level nearly 1.3 billion people are poor, living on less than US \$1.9 per day (Hughes et al, 2004). In addition, nearly $70 \%$ of the world poor, deprived and economically vulnerable people are living in rural areas (Moghadam, 2005), who lack basic necessities and services of life. Usually, people migrate in order to obtain better livelihood opportunities. In this context, poverty and migration are closely related and in economically poor countries and societies, migration is a result of poverty and unsustainable livelihoods. In this way, migration mostly takes place in search of better economic opportunities (Kenkel, 1997 \& Parveen, 1993). An extract from a field interview:

"I belong to a poor family and migrated Karachi in search of employment. Migration was a difficult and troublesome experience for me. In the absence of family control I was involved in drugs and also used injectable drugs. After doing it for several years, I was diagnosed as HIV infected in a routine check up for a minor infection. The curse of poverty, illiteracy and of migrant life ruined my life forever. It is also agonizing that I also infected my wife" (1-S-2)

Migration is a significant source of livelihood and unlocks doors of many opportunities and benefits for poor people in developing coun- tries. Each year, millions of people travel within and outside their countries in search of work, better life opportunities, to avoid poverty, to escape conflict and to acquire quality education (Ratha, 2005). In many developing countries, workers' remittances has been an important source of income generation, poverty alleviation and improved life standard for migrants and their households (Cuillier \& Piotrowski, 2009). Many households use migration as a livelihood strategy for reducing the economic risks in areas where insurance and capital markets are not present or are imperfect. An extract from field interview:

"In absence of proper employment opportunities at my village I migrated to Lahore in order to earn a livelihood. It is indeed an alternate livelihood opportunity and source of income for me. I had no livelihood opportunities in the hard and barren areas of rural life. But sometime migration proves more consequential and I borrow difficulties instead of amenities" (3-H-7)

Generally, migration has been seen as a flight from poverty and people migrate to other parts of the country or visit abroad in order to find better employment. Although, migration is a source of earning remittances and socio-economic uplift, however, it is also associated with many risks and vulnerabilities. In many cases, migrants are: deceived in the name of jobs; are denied grant of job contract; face confiscation of documents. While in many instances they are exposed to: harassment; discrimination; derogatory working condition; health issues; violence; exploitation (Arif, 2005; Rogers, Anderson \& Clark, 2009). An extract from a field interview:

"Being an elder son of my parents I got married at 18 years. I was responsible for providing financial support to the family. After one year of marriage I left for Malaysia for work in order to fulfill financial requirements of my family. It was during my migrant life in Malaysia that I maintained illegal sexual relation with a prostitute and acquired the infection" (4-S-1)

Although, migration has been recognized as a significant livelihood strategy, and people mostly migrate in order to escape poverty, however, migrants face certain problems such as exploitation, deprivation, absence of social protec- 
tion and exposure to health vulnerabilities including exposure to HIV/AIDS.

\section{Migrant's Dangerous Working Condition and Risks of HIV/AIDS Transmission}

In their destinations, migrants are exposed to insecure living and working condition that increase their exposure to adverse health conditions (Parrado \& Flippens, 2010). Besides, majority of migrants are concentrated in the dirty, dangerous and difficult jobs, with little or no occupational and physical safety and protection. Also, a large number of migrant workers live and work in geographically isolated areas, such as construction sites, mining, seaports, or in rural agricultural areas in the destination areas or countries, where health facilities and services are non-existent, limited or inaccessible (ILO, 2014). Similar views were also shared by a respondent during a field interview. An extract from interview:

"During my migrant life in UAE my living and working place was insecure without any proper health and hygiene facilities. Thirty workers were placed in four rooms without basic facilities of life. The environment was dusty and many laborers fell ill. The reality is that I acquired the infection during my migrant life. It was my poverty that compelled me to leave home. If I would have not been poor I would not been infected. My life has been ruined as I have not hope of recovery form HIV" (6-A-8)

Many migrant workers are employed in such derogatory and exploitative jobs where the locals/natives are unwilling to accept and take these jobs. Also, a majority of migrant workers are engaged in mining, loading, unloading, and difficult construction sectors, where the ratio of occupational accidents, injuries, disabilities, and exposure to various infections as well as deaths are higher (Corno \& Walque, 2012). Besides, domestic migrant workers were found highly vulnerable to HIV as their work is not high paid and they may also be subject to abuse by their employers ranging from excessive working hours to delays in payment, as well as sexual harassment, violence and rape (Mahdavi, 2013). Reflecting upon this a respondent uttered:

"I was working with a petty contractor as a laborer in very dusty and unsafe environment. My job was lifting heavy broken pieces of steel and iron, without any safety kits. Besides, sleeping and living place was very narrow, dirty and unhygienic, with solid waste lying all around. There was no check from employer after working hours. It was during this time that I got severe UTI, which was later on diagnosis as HIV by the doctor" (7Z-6)

There have been incidences of employers forcefully pushing workers into informal and irregular economic activities, including sex work, which increase their vulnerabilities to HIV (Mahdavi, 2013). Migrant labor face harsh attitude from employers in countries with the "kafala system" and labor disputes with an employer can result in deportation, criminal prosecution as well as harsh punishment. Similarly, there have been incidences of food deprivation and inadequate living conditions (Gamburd, 2010), while those migrants diagnosed as HIV positive are deported without treatment or counseling (Weine, Bahromov \& Mirzoev, 2008. In this context, field information also show similar findings and respondent reported that:

"The working condition was very adverse, and sometime I thought of committing suicide to escape from these desperate working and living conditions. There was no medical care for heat stroke, fever, infections and workplace injuries, and he was given "Panadol" for every disease including urinary tract infection. I asked my camp boss for permission but he refused and told me to go and continue your work" (11-Y-8)

Conclusively, migrants face several problems in their living and working environment, and they are exposed to health hazards and acquire various infections without having proper access to medical services.

\section{Migrnts' Human Rights violation and their Exposure to HIV/AIDS}

Migrant populations at large are exposed to human rights violation. Migrants are away from their homes and they have no control over receiving adequate support and care services once they are infected. They also lack power to minimize or change their risks of exposure to HIV (Gruskin \& Loff, 2002). Migration in itself is not increasing HIV vulnerability rather the social context that drives migrant behavior is re- 
sponsible for transmission of HIV among migrants. In the majority cases, migrant's are not treated as fully humans and they are deprived of their basic human rights (Palo, 2008). Field information also indicates that migrant's rights are violated. An extract from an interview:

"I visited Malaysia on a driver visa but my employer intimidated me to work as a gardener and home cleaning servant. At first I was paid on time but later on the employer stopped payment. On my asking for payment, the employer told me that he would not pay him. He also threatened me that if I asked for payment he would refuse to provide me with an exit permit until I signed an agreement saying that all wages that were due to him had been paid" (1-J-7)

Human rights violation are found at many levels, such as residence is not allowed without job, limited or no social benefits or medical care, no grant of right to appeal, while deportation is permitted at any time without explaining any reason for it. Further, migrants are not allowed to own property, start or join trade unions, and there exist a sharp contrast between the benefits that a foreigner and a national get in these states. While migrant workers are also subjected certain abuses such as beatings, verbal abuse, and confiscation of documents, forced labor, and thus making them physically and psychologically stressed (Moyce \& Schenker, 2018). Similar views were also shared by a respondent's during a filed interviews:

"I arranged a Saudi labor visa for a construction company. For the first 3 months I waited for the work to begin. After start of the work, I worked for 12-hour for my sponsor, carrying construction materials in a project in the desert. For three months I was not paid. When I told my sponsor that I am not willing to continue work, until I was paid, my sponsor asked, Are you here to have fun or work? He threatened me, to be arrested by the police and I won't be able to go home" (5-A-7)

Another respondent also shared a similar opinion:

"The kafala or sponsorship system of work permits is common in Bahrain with significant restrictions on migrants. The kafeel exerts full control over the migrant workers and confiscated his passports and travel documents. I was placed in a construction company with a harsh supervisor, who rarely cared about my health and such circumstances made me vulnerable to HIV infection" (1-H-2)

Usually, migrant workers constantly face discrimination in employment, which has enormous effects on migrants particularly on their health. They are at particular risk of discrimination because their nationalities and treated as exploitable, and are seen as replaceable, cheap, weak, flexible and submissive labor. Such discriminatory practices also lead to violence, harassment, poor working condition, and low adherence to treatment which increase their vulnerability to HIV/AIDS.

\section{Conclusions}

This study concludes that poverty compels people to migrate in order to earn livelihood and search for a better life. Migration in part has contributed to improved life standard in terms of earning remittances, however; in most cases migrants found themselves subject to exploitation, deprivation, and risky behaviors in their new destination. Importantly, migrants stay away from the traditional home environment and traditional control exposes them to risky behaviors and made them vulnerable to numerous infections including HIV. It was also found that migration related problems such as difficulty in accessing medical and prevention services facilitated the transmission of HIV/AIDS among migrants. It was also reported that migrants frequently worked in dirty, dangerous, and difficult jobs, having little or no occupational and physical safety, protection or health services, compared to natives or locals. Mostly, migrants work in such sectors where the ratio of occupational accidents, injuries, disabilities, exposure to infections as well as deaths was found higher, while a majority of migrant workers were deprived of quality food, they were provided substandard sleeping accommodations. Also, migrant human rights were violated in numerous ways such as restricted access to housing, social benefits, medical care, no right to appeal, starting or joining unions, owning property, while deportation is permitted at any time without explaining any reason for it. The kafala system 
was reported as a root cause and problematic aspect of migration to the Gulf States, in which the kafeel exerts full control over migrant workers, exploiting them and violating basic human rights.

\section{References}

1. UNAIDS A (2002) Conceptual Framework and Basis for Action: HIV/AIDS Stigma and Discrimination. World AIDS Campaign 2002-2003. Joint United Nations Program on HIV/AIDS (UNAIDS. (2002). Report on the global HIV/AIDS epidemic. UNAIDS.

2. SLDDIQUI R, KEMAL A R (2006) Remittances, trade liberalization, and poverty in Pakistan: The role of excluded variables in poverty change analysis. The Pakistan Development Review, 383-415.

3. PIOTROWSKI M (2009) Migrant remittances and skipped generation households: Investigating the exchange motive using evidence from Nang Rong, Thailand. Asian and Pacific Migration Journal, 18(2), pp. 163196.

4. PARKER R (2001) Sexuality, culture, and power in HIV/AIDS research. Annual Review of Anthropology, 30(1), pp. 163-179.

5. CONNELL J (2006) Migration, dependency and inequality in the Pacific: Old wine in bigger bottles? (Part 1). Globalization and governance in the Pacific Islands, pp. 59-80.

6. SIDDIQUI T (2012) Impact of migration on poverty and development.

7. SINGH D P (2009) Poverty and migration: does moving help? Urban poverty report.

8. RAVENSTEIN E G (1885) The laws of migration. Journal of the statistical society of London, 48(2), pp. 167-235.

9. SKELDON R (1997) Migration and Development: A Global Perspective, Essex: Longman.

10. STARK O, BLOOM D E (1985) The new economics of labor migration. The American Economic Review, 75(2) pp. 173-178.

11. DOUGLAS S, MASSEY J A, GRAEME HUGO A K, TAYLOR J E (2009) Worlds in Motion. Understanding International Migration at the End of the Millennium.

12. MASSEY D S, GOLDRING L, DURAND J (1994) Continuities in transnational migration: An analysis of nineteen Mexican com- munities. American Journal of Sociology, 99(6), pp. 1492-1533.

13. MAHDAVI P (2013) Gender, Labor and the Law: the nexus of domestic work, human trafficking and the informal economy in the United Arab Emirates. Global Networks, 13(4), pp. 425-440.

14. SALAMA S (2007) Hundreds of workers forced to live in attics. Gulf News, 2, p. 19.

15. PARRADO E A, FLIPPEN C (2010) Community attachment, neighborhood context, and sex worker use among Hispanic migrants in Durham, North Carolina, USA. Social Science \& Medicine, 70(7), 1059-1069.

16. CASTLES S (1998) The age of migration: International population movements in the modern world. Macmillan International Higher Education.

17. HUGHES C, AVOKE S K (2010) The elephant in the room: Poverty, disability, and employment. Research \& Practice for Persons with Severe Disabilities, 35(1-2) pp. 514.

18. CASTLES S (2002) Migration and community formation under conditions of globalization. International Migration Review, 36(4), pp. 1143-1168.

19. SULIMAN S (2017) Migration and Development after 2015. Globalizations, 14 (3), pp. 415-431.

20. STANDING G (2008) The ILO: An agency for globalization?. Development and Change, 39(3) pp. 355-384.

21. TACOLI C, MCGRANAHAN G, SATTERTHWAITE D (2015) Urbanization, rural-urban migration and urban poverty. Human Settlements Group, International Institute for Environment and Development.

22. MBIRIMTENGERENJI N D (2007). Is HIV/AIDS epidemic outcome of poverty in sub-Saharan Africa?. Croatian medical journal, 48(5) p. 605.

23. DAVIES A A, BASTEN A, FRATTINI C (2009) Migration: a Social Determinant of the Health of Migrants. Eurohealth, 16(1), 10-12.

24. CARNEY D (1998) Sustainable livelihoods. Sustainable Livelihoods: What contribution can we make.

25. SHERBININ A (2008) Is poverty more acute near parks? An assessment of infant mortality 
rates around protected areas in developing countries. Oryx, 42(1) pp. 26-35.

26. SKELDON R (1997) Rural-to-urban migration and its implications for poverty alleviation. Asia-Pacific Population Journal, 12(1) p. 3.

27. WOOD S (Ed.) (1982) The Degradation of work? : skill, deskilling, \& the Labor Process. Hutchinson Radius.

28. MASSEY D S, PARRADO E A (1998) International migration and business formation in Mexico. Social Science Quarterly, pp. 1-20.

29. STARK O, BLOOM D E (1985) The new economics of labor migration. The american Economic Review, 75(2) pp. 173-178.

30. CUILLIER D, PIOTROWSKI S J (2009) Internet information-seeking and its relation to support for access to government records. Government Information Quarterly, 26(3) pp. 441-449.

31. ROGERS A, ANDERSON B, CLARK N (2009) Recession, vulnerable workers and immigration. Retrieved April, 12, 2010.

32. PARRADO E A, FLIPPEN C (2010) Migration and sexuality among Mexicans: Implications for the diffusion of HIV. Journal of Social Issues, 66, pp. 175-195.

33. CORNO L, DE WALQUE D (2012) Mines, migration and HIV/AIDS in Southern Africa. Journal of African Economies, 21(3) pp. 465-498.

34. WEINE S, BAHROMOV M, MIRZOEV A (2008) Unprotected Tajik male migrant workers in Moscow at risk for HIV/AIDS. Journal of Immigrant and Minority Health, 10(5) pp. 461-468.

35. GRUSKIN S, LOFF B (2002) Do human rights have a role in public health work?. The Lancet, 360(9348) p. 1880.

36. PALO S (2008) Labor Migration and HIV/AIDS Vulnerability: An overview of International research. Indian Journal of Social Work, 69(3) p. 369.

37. MOYCE S C, SCHENKER M (2018) Migrant workers and their occupational health and safety. Annual review of public health, 39 pp. 351-365.

38. PATTON M Q (2002) Two decades of developments in qualitative inquiry: A personal, experiential perspective. Qualitative social work, 1(3) pp. 261-283.
39. SHAMOO A E, RESNIK D B (2009). Responsible conduct of research: Oxford University Press. 